\title{
Glue Technologies for Space Systems: An Introduction to a New AESS Technical Panel
}

\author{
Claudio Sacchi, Senior Member, IEEE, Marina Ruggieri, Fellow, IEEE, Kar-Ming Cheung, Mario \\ Marchese, Senior Member, IEEE, Fabrizio Granelli, Senior Member, IEEE, Vlad Popescu, Member, IEEE, \\ Michael Rice, Fellow, IEEE, Maurizio Murroni, Senior Member, IEEE, Nicola Conci, Member, IEEE, Christian \\ Schlegel, Fellow, IEEE, Tommaso Rossi, Michael Noble, Member, IEEE
}

\begin{abstract}
This article aims at introducing to the readers of the AES Magazine the recently constituted technical panel: "Glue Technologies for Space Systems". A short overview of the technologies considered in the panel will be provided, along with panel vision and perspectives shared with the founder members. Some information about panel meetings and participation rules will conclude the article.
\end{abstract}

\section{INTRODUCTION AND MOTIVATIONS}

$\mathbf{T}$ HE recent change of perspective of aerospace communications, known also as "Space 2.0" [1] straightforwardly introduced the concept of "Space Intelligence", meaning the capability of building a networked cognitive Space environment, able at supporting the endeavors of researchers and developers working in the field of Space technology. As shown in Fig. 1 the Space environment becomes a kind of ecosystem where surface networks (in the figure, terrestrial networks are indicated, but the same scenario could be conceived, e.g. for Martian networks) and space networks will form together a unique integrated infrastructure targeting the global, ubiquitous, resilient, and broadband coverage of ICT services. Space Network Intelligence is actually the capability of the Space segment of dynamically configuring itself on the basis of the connectivity requirements coming from the surface network infrastructures.

It is evident that such a renewed vision involves the necessity of a superior level of integration among heterogeneous

C. Sacchi, F. Granelli and N. Conci are with the Department of Information Engineering and COmputer Science (DISI), University of Trento, Trento, Italy, 38123 e-mail: claudio.sacchi@unitn.it, fabrizio.granelli@unitn.it, nicola.conci@unitn.it.

M. Ruggieri and T. Rossi are with the Department of Electronic Engineering/CTIF of University of Roma Tor Vergata, Rome, Italy, 00185, e-mail: ruggieri@uniroma2.it, tommaso.rossi@uniroma2.it.

K-M. Cheung is with the Jet Propulsion Lab, Pasadena, CA, 91109, e-mail: kar-ming.cheung@jpl.nasa.gov.

M. Marchese is with the Department of Electrical, Electronic, and Telecommunications Engineering and Naval Architecture (DITEN), University of Genoa, Genoa, Italy, 16145 e-mail: mario.marchese@unitn.it.

V. Popescu is with the University of Transilvania, Brasov, Romania, 500019 e-mail: vlad.popescu@unitbv.ro.

M. Rice is with the Department of Electrical and Computer Engineering of the Brigham Young University, Provo, UT, 84602, e-mail: mdr@byu.edu.

C. Schlegel is with HCDC llc, Park City, UT, and Acoubit Communications, Halifax, NS, Canada, e-mail: christian.b.schlegel@gmail.com.

M. Murroni is with the Department of Electrical and Electronic Engineering (DIEE) of University of Cagliari, Italy, 09123, e-mail: murroni@ diee.unica.it.

M. Noble is with L3 Technologies, New York, NJ e-mail: Michael.Noble@L3T.com.

Manuscript received November 29, 2019, revised on December 4, 2019.

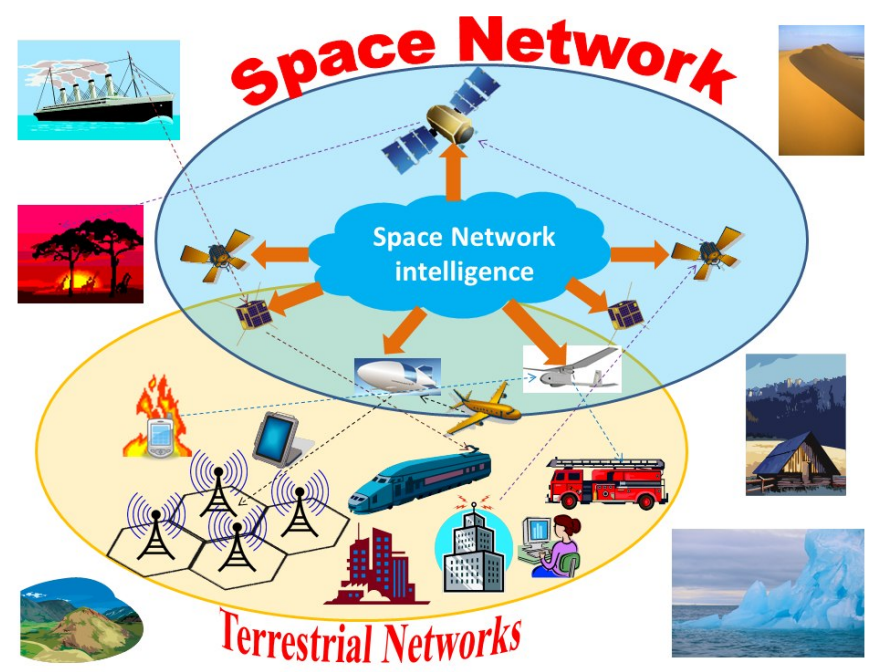

Fig. 1. Space 2.0 vision: pictorial description.

networked processing entities. "Glue technologies" will offer the necessary support to fulfill such a fundamental requirement. Glue technology, as with global enterprises, integrates the subsidiaries and other producing units, saving their own need of autonomy [2]. In the specific Space framework, "Glue Technologies" constitutes the necessary common platform for the innovative systems based on Space components (satellites, UAV, rover, landers, orbiters, etc.) that will be deployed in the near future in various application fields (satellite and aerospace communications, interplanetary communications, planet exploration, Internet of Space Things, etc.). This is the reason why AESS decided in April 2019 to constitute a new panel called "Glue Technologies for Space Systems". Rather than mere "technologies", the panel will consider "technological tools" that will be used (and reused) in different and heterogeneous sectors of Space Science and Engineering.

The most important "glue" in Space ICT is the exchange of data among different entities that should work in seamless networked manner. But, also data and signal processing constitutes another form of "glue" that is essential to connect the remote processing machines to the human comprehension and investigation of what happens in the Space.

In this article, the various glue technologies for space systems will be briefly introduced (Section II) and, then, the founder members will share their own vision of the panel in 
terms of motivations and future achievements to be pursued (Section III). Section IV and section V will conclude the article with the updated list of the panel adjunct members and some other useful information (panel meeting organization, panel participation rules, etc.)

\section{OVERVIEW OF GLUE TECHNOLOGIES FOR SPACE SYSTEMS}

In the following, a brief overview of the technical areas of the panel is provided, along with some reference to relevant works published in the literature, highlighting developments, potentials, open issues and applications of the "glue" technologies.

\section{A. Broadband space transmissions}

The most recent trends in broadband satellite data transmissions are considering the exploitation of Extremely High Frequency (EHF) bandwidth portions in order to boost link capacity (see, e.g., ESA Alphasat experiment concerning a $\mathrm{Q} / \mathrm{V}$ band payload [3]). The synergy between EHF transmission and multibeam satellites could break the wall of terabit capacity in the Sky, paving the road to a plethora of applications, from UHDTV broadcasting [4] to multimedia streaming in $5 \mathrm{G}$ scenarios [5]. A lot of research work is currently done about the mitigation of atmospheric propagation effects that is a still an open issue in these frequency ranges.

\section{B. Softwarization of space networking}

In order to bring intelligence to Space, a substantial step ahead is required in terms of augmented flexibility and reprogrammability of the Space network segment. In such a framework, Software-Defined Radio (SDR) and SoftwareDefined Networking (SDN) reprensent the key technologies. Most recent contributions, published in the literature, consider the SDN-based seamless integration of heterogeneous satellite links (free-space optical and radio) [6], reconfigurable CubeSat payloads based on SDR [7], and the integration of satellite networking in the $5 \mathrm{G}$ ecosystem, obtained by means of SDN tools [8].

\section{Internet of Remote Things (IoRT) and Internet of Space Things (IoST)}

A second revolution in Internet technology is growing around the concept of Internet of Things (IoT). Satellite communications may potentially play an important role in IoT. Indeed, smart objects are often remote or dispersed over wide geographical areas, or they are inaccessible. Such a situation is referred in [9] as Internet of Remote Things (IoRT). In such a framework, satellite communication would offer a broadband cost-effective solution for the interconnection of networks of smart objects with the rest of the world. Recent developments are considering IoRT in a wider vision encompassing smart environments in the deep space. In such a framework, we can speak about Internet of Space Things (IoST). An interesting example has been shown in [10], where IoT and Wireless Power Transmission (WPT) are employed in Deep-Space exploration.

\section{Seamless integration of intelligent aerial networks and with} cognitive and softwarized sky networks

This is a very emerging topic in aerospace networking with a lot of potential for high added-value applications. The multitude of drones and UAVs flying over our heads configure a "smart cloud" capable of fulfilling advanced monitoring tasks in every kind of emergency, provided that coordination and seamless integration with long-range Space networks is guaranteed. In [11], a valuable example has been presented, describing the use of satellite-based Cloud Radio Access Network (CRAN) in order to efficiently manage safety-critical information exchange from ground sensors, UAVs and remote control centers in border monitoring applications.

\section{E. Augmented 3D reality for manned exploration missions}

In the days of the $50^{t h}$ anniversary of the Moon walk of $\mathrm{N}$. Armstrong and E.A. Aldrin, future Space missions are being planned. The very ambitious target of these early millennium decades is to reach Mars with a manned crew. Techniques of augmented 3D reality may provide a valuable support to the crew training, virtually reproducing the Mars surface environment. An example published in the literature is shown in [12], where a Virtual Astronaut is created as an interactive virtual 3D environment to support the Mars Exploration Rover mission.

\section{F. End-to-end system considerations of Space systems}

Much effort has been spent to promote the "system engineering" aspects of space system. However this effort is mostly qualitative/process-oriented, and are on the pragmatic side. In order to provide a more effective end-to-end system assessment of Space systems, the panel intends to promote the investigation of more formal and analytical approaches, using e.g. advanced statistical techniques, probabilistic inference, optimization methods, etc. Some examples are joint design for the Galileo's error-correction and data compression system [13], statistical link analysis and margin policy for dynamic links [14], and joint data-layer and network-layer smart transmission protocols for reliable communications for fading channels [15].

\section{G. Integrated communication, navigation and sensing}

In the past few decades, communications and navigation have been developed in separate paths. But for space system, it is highly desirable to integrate the two systems together. For robotic and human space explorations beyond Earth, e.g. Moon and Mars, it is desirable to establish a low-complexity relay infrastructure (with a small number of orbiters) that provides integrated communications and navigation services to the visiting spacecraft [16] [17], [18]. The low-complexity integrated communications and navigation approach can also be useful for Earth's "GPS-denied" applications, and for GPSaugmentation in urban canyon environments [19]. Sensing and radars represent other actors in this integration process. Recent works are considering these aspects [20], [21], [22] [23], in the framework of safety-critical applications like e.g. maritime safety, autonomous vehicle guidance and emergency rescue. 


\section{H. Advanced signal processing and data fusion techniques for Space applications}

Data fusion is the typical "glue" of advanced signal processing tasks, as it seamlessly integrates and processes information coming from heterogeneous sensors and signal sources. As far as Space applications are concerned, recent examples have been demonstrated about radiometric and inertial data fusion for deep space navigation, [24], SAR. optical and LIDAR data fusion for high resolution mapping of protected areas [25] and multisensor satellite image fusion for the study of climatic changes [26].

\section{PANel VISION (FROM THE PANEL FOUNDER MEMBERS)}

The vision and the perspectives of the panel, expressed by the founder members, are shown in Tab.1.

\section{UPDATED LIST OF THE ADJUNCT PANEL MEMBERS}

- Mohammed-Slim Alouini (King Abdullah University of Science and Technology, Saudi Arabia Kingdom).

- Michael Devetsikiotis (University of New Mexico, Albuquerque, NM).

- Giorgia Parca (Italian Space Agency, ASI, Italy).

- Giuseppe Codispoti (Italian Space Agency, ASI, Italy).

- Paolo Tortora (University of Bologna, Italy).

- Barry Evans (University of Surrey, UK).

- Eugene Grayver (Aerospace Corporation, El Segundo, CA).

- Simone Morosi (University of Firenze, Italy).

- Sean Malek (University of Dayton, Dayton OH).

- Riccardo Bassoli (Technical University of Dresden, Germany).

\section{PANel MeEtings AND PARTICIPATION RULES}

Two panel meetings per year have been planned. The first one is organized in the month of March during the IEEE Aerospace Conference in Big Sky (MT) (IEEE Aerospace Conference is the "home conference" of the panel). The second meeting is organized in Rome (Italy) in September. The location of the September meeting is the Italian Space Agency (ASI) headquarter. The participation to the meetings is possible both in person and in remote.

The panel is open to all interested persons, coming from academia, industry, space agencies etc. It is not required the IEEE membership. Members of other technical societies are welcome. However, only active AESS members may serve as chair/vice-chair. If you want to join the panel, please send an email to the panel organizers Claudio Sacchi (claudio.sacchi@unitn.it) and Marina Ruggieri (ruggieri@uniroma2.it).

\section{REFERENCES}

[1] C. Sacchi, K. Bhasin, N. Kadowaki, and F. Vong, "Toward the "space 2.0" era [guest editorial]," IEEE Communications Magazine, vol. 53, no. 3, pp. 16-17, March 2015 .

[2] P. Evans, "Management development as glue technology," Human Resource Planning, vol. 15, pp. 85-106, 011992.
[3] G. Codispoti, G. Parca, M. Ruggieri, T. Rossi, M. De Sanctis, C. Riva, and L. Luini, "The role of the italian space agency in investigating high frequencies for satellite communications: The alphasat experiment," International Journal of Satellite Communications and Networking, vol. 37, no. 5, pp. 387-396, 2019. [Online]. Available: https://onlinelibrary.wiley.com/doi/abs/10.1002/sat.1252

[4] C. Sacchi, T. Rossi, M. Murroni, and M. Ruggieri, "Extremely high frequency (ehf) bands for future broadcast satellite services: Opportunities and challenges," IEEE Transactions on Broadcasting, pp. 1-18, 2019.

[5] A. Mudonhi, C. Sacchi, and F. Granelli, "Sdn-based multimedia content delivery in 5g mmwave hybrid satellite-terrestrial networks," in 2018 IEEE 29th Annual International Symposium on Personal, Indoor and Mobile Radio Communications (PIMRC), Sep. 2018, pp. 1-7.

[6] E. Cianca, T. Rossi, M. Ruggieri, M. Presi, E. Ciaramella, L. Luini, C. Sacchi, G. Parca, and G. Codispoti, "Softwarization and virtualization as enablers for future ehf/fso high throughput satellites," in 2018 IEEE Global Communications Conference (GLOBECOM), Dec 2018, pp. 1-6.

[7] J. L. Alvarez, M. Rice, J. R. Samson, and M. A. Koets, "Increasing the capability of cubesat-based software-defined radio applications," in 2016 IEEE Aerospace Conference, March 2016, pp. 1-10.

[8] L. Boero, R. Bruschi, F. Davoli, M. Marchese, and F. Patrone, "Satellite networking integration in the $5 \mathrm{~g}$ ecosystem: Research trends and open challenges," IEEE Network, vol. 32, no. 5, pp. 9-15, Sep. 2018.

[9] M. De Sanctis, E. Cianca, G. Araniti, I. Bisio, and R. Prasad, "Satellite communications supporting internet of remote things," IEEE Internet of Things Journal, vol. 3, no. 1, pp. 113-123, Feb 2016.

[10] R. Correia, D. Belo, and N. B. Carvalho, "Iot/wpt developments in space exploration," in 2018 Asia-Pacific Microwave Conference (APMC), Nov 2018, pp. 79-81.

[11] R. Bassoli, C. Sacchi, F. Granelli, and I. Ashkenazi, "A virtualized border control system based on uavs: Design and energy efficiency considerations," in 2019 IEEE Aerospace Conference, March 2019, pp. $1-11$.

[12] J. Wang and K. J. Bennett, "A virtual reality study on santa maria crater on mars," in 2013 IEEE Virtual Reality (VR), March 2013, pp. 105-106.

[13] K. Cheung, K. Tong, and M. Belongie, "End-to-end system consideration of the galileo image compression system," in IGARSS '96. 1996 International Geoscience and Remote Sensing Symposium, vol. 2, May 1996, pp. 1035-1038 vol.2.

[14] K. M. Cheung, "The role of margin in link design and optimization," 2015 IEEE Aerospace Conference, pp. 1-11, 2015.

[15] K. Cheung and T. Choi, "Statistical arq link analysis and planning for dynamic links," in 2016 IEEE Aerospace Conference, March 2016, pp. $1-8$.

[16] K. Cheung, C. Lee, W. Jun, and G. Lightsey, "Single-satellite doppler localization with law of cosines (loc)," in 2019 IEEE Aerospace Conference, March 2019, pp. 1-12.

[17] _ _ "Single-satellite real-time relative positioning for moon and mars," in International Aeronautical Congress 2019, October 2019.

[18] _ _ "Single-satellite real-time positioning for balloon and helicopter for aerial exploration in extraterrestrial atmosphere," in International Aeronautical Congress 2019, October 2019.

[19] _ _ "Localizing in urban canyons using joint doppler and ranging and the law of cosines method," in ION GNSS + 2019 Conference, September 2019.

[20] H. Zhengqun, P. Jun, and L. Chang, "A software design of central processing in integrated system of satellite navigation and communication," in 2016 3rd International Conference on Information Science and Control Engineering (ICISCE), July 2016, pp. 1249-1252.

[21] Chun-Hao Huang and Shwu-Jing Chang, "Onboard integration of maritime safety information for navigation display and route safety," in 2012 12th International Conference on ITS Telecommunications, Nov 2012, pp. $461-465$.

[22] W. Zhang, "Sensing for autonomous vehicle navigation," in 2009 Conference on Lasers and Electro-Optics and 2009 Conference on Quantum electronics and Laser Science Conference, June 2009, pp. 1-2.

[23] E. Del Re, S. Jayousi, S. Morosi, L. S. Ronga, M. De Sanctis, E. Cianca, M. Ruggieri, E. Falletti, A. Iera, G. Araniti, and C. Sacchi, "Salice project: Satellite-assisted localization and communication systems for emergency services," IEEE Aerospace and Electronic Systems Magazine, vol. 28, no. 9, pp. 4-15, Sep. 2013.

[24] Y. Meng, W. Lei, L. Bian, Y. Wang, T. Yan, and G. Wang, "One-way deep space navigation with radiometric and inertial data fusion," in 2017 20th International Conference on Information Fusion (Fusion), July 2017, pp. 1-5.

[25] R. Guida, J. Marcello, and F. Eugenio, "Sar, optical and lidar data fusion for the high resolution mapping of natural protected areas," in 2015 IEEE 
International Geoscience and Remote Sensing Symposium (IGARSS), July 2015, pp. 3306-3309.

[26] N. Chang, K. Bai, S. Imen, C. Chen, and W. Gao, "Multisensor satellite image fusion and networking for all-weather environmental monitoring," IEEE Systems Journal, vol. 12, no. 2, pp. 1341-1357, June 2018. 


\begin{tabular}{|c|c|c|}
\hline FOUNDER MEMBER & $\begin{array}{l}\text { PLEASE, EXPLAIN THE REASON WHY DID YOU } \\
\text { DECIDE TO JOIN THE PANEL }\end{array}$ & $\begin{array}{c}\text { PLEASE, EXPRESS YOUR PERSONAL FEELING ABOUT } \\
\text { WHICH OUTCOMES DO YOU EXPECT IN THE NEAR } \\
\text { FUTURE FROM THE PANEL ACTIVITIES }\end{array}$ \\
\hline & $\begin{array}{l}\text { I am a member of the AESS and this panel is my natural } \\
\text { technical "home." I find interesting the problems, } \\
\text { techniques, and challenges of satellite communication } \\
\text { systems and want to be a part of the effort to apply } \\
\text { different technologies to improving the capabilities and } \\
\text { performance of satellite systems. }\end{array}$ & $\begin{array}{l}\text { I hope the panel activities raise awareness of the interesting } \\
\text { problems in satellite communication systems, especially } \\
\text { with young professionals looking for interesting careers and } \\
\text { young graduate students looking for challenging problems } \\
\text { whose solution can make a difference. }\end{array}$ \\
\hline \multicolumn{3}{|l|}{$\begin{array}{l}\text { Michael Rice, Brigham Young } \\
\text { University, Provo, UT, Fellow } \\
\text { IEEE, AESS member }\end{array}$} \\
\hline $\begin{array}{l}\text { Mario Marchese, University of } \\
\text { Genoa, Italy, IEEE Senior } \\
\text { member, ComSoc member }\end{array}$ & $\begin{array}{l}\text { The idea to be part of an international panel to foster } \\
\text { research and technical activities about satellite } \\
\text { communication and networking is really stimulating. } \\
\text { One of the key points is to fully understand the satellite } \\
\text { role in the future } 5 \mathrm{G} \text { and to individuate a possible } \\
\text { roadmap to get a full integration of satellites in the } 5 \mathrm{G} \\
\text { environment. Thanks to their intrinsic ubiquity and } \\
\text { broadcasting capabilities, satellite networks can play } \\
\text { multiple roles in 5G, both as main communication } \\
\text { segment for rural and risky areas, aircrafts, vessels, and } \\
\text { trains, and as a mean to provide additional connectivity } \\
\text { and bandwidth. Their integration in the 5G environment } \\
\text { poses new challenges that this panel can help } \\
\text { investigating through the promotion of courses, schools, } \\
\text { meetings, conferences, journals where people both from } \\
\text { industry and academy can openly discuss. }\end{array}$ & $\begin{array}{l}\text { In the long-term the panel should be aimed at: disseminating } \\
\text { knowledge, in particular to younger generations; } \\
\text { technologists and scientists training; stimulating discussions } \\
\text { and direct knowledge exchange. In this view, short-term } \\
\text { outcomes should be the endorsement of courses, schools and } \\
\text { meetings about dedicated selected topics, while medium- } \\
\text { term outcomes should be the organization of conference } \\
\text { sessions and panels where experts may communicate the } \\
\text { state of the art and new ideas about hot advanced topics, and } \\
\text { of special issues in journals and magazines to establish } \\
\text { seminal knowledge. }\end{array}$ \\
\hline
\end{tabular}




\begin{tabular}{|c|c|c|}
\hline $\begin{array}{l}\text { Kar-Ming Cheung, Jet } \\
\text { Propulsion Lab, Pasadena, CA, } \\
\text { IEEE Senior Member }\end{array}$ & $\begin{array}{l}\text { Much research and development (R\&D) in the fields of } \\
\text { communications and networking of space systems has a } \\
\text { tendency on focusing on one specific capability, and do } \\
\text { not consider its interactions with other functions in the } \\
\text { signal processing and data flow chain, and with its } \\
\text { environment. This parochial view sometimes impairs the } \\
\text { efficiency and the utility of that capability in operations. } \\
\text { System engineering and architecture are after-thoughts in } \\
\text { many cases, and the efforts are mostly } \\
\text { qualitative/process-oriented, and are empirical, hands-on, } \\
\text { and pragmatic in nature. The "glue technologies" panel } \\
\text { can help to advocate the importance of end-to-end } \\
\text { system considerations in the early stage of the R\&D } \\
\text { efforts. } \\
\text { In the past few decades, communications and navigation } \\
\text { systems have developed along separate paths. Now there } \\
\text { are very good communication radios and systems, and } \\
\text { there are very good Earth-based navigation infrastructure } \\
\text { and systems, but they are separated. For robotic and } \\
\text { human explorations beyond Earth, e.g. Moon and Mars, } \\
\text { it is desirable to establish a low-complexity relay } \\
\text { infrastructure (with a small number of orbiters) that } \\
\text { provides integrated communications and navigation } \\
\text { services to the visiting spacecraft. The low-complexity } \\
\text { integrated communications and navigation approach can } \\
\text { also be useful for Earth's "GPS-denied" applications, } \\
\text { and for GPS-augmentation in urban canyon } \\
\text { environments. This panel can help to promote the } \\
\text { system concept of integrated communications and } \\
\text { navigation for Earth and beyond Earth's space } \\
\text { applications. }\end{array}$ & $\begin{array}{l}\text { On the end-to-end system considerations of space systems, } \\
\text { this panel should promote using vigorous and formal } \\
\text { techniques in statistical analysis, probability inference, and } \\
\text { optimization methods in system analysis and trade, } \\
\text { especially in the early stage of system design and } \\
\text { architecture. This would facilitate infusion of advance } \\
\text { technologies into space system operations. } \\
\text { For integrated communications and navigation, this panel } \\
\text { should promote new signal structures and signal processing } \\
\text { methods that are useful for both communications and } \\
\text { navigation. This would enable low-complexity planetary } \\
\text { relay network infrastructure, and greatly reduce users' } \\
\text { burden in terms of Size, Weight, and Power (SWaP) in } \\
\text { communications and navigation. }\end{array}$ \\
\hline
\end{tabular}




\begin{tabular}{|c|c|c|}
\hline 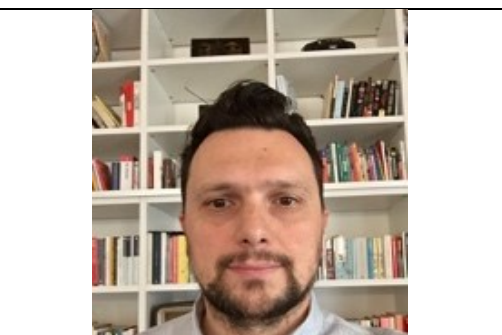 & $\begin{array}{l}\text { I am a member of the IEEE Signal Processing Society, } \\
\text { being my background in the area of image and video } \\
\text { processing. What I find particularly interesting in this } \\
\text { panel is the chance of applying my research to a new } \\
\text { extremely challenging domain. I strongly believe that the } \\
\text { computer vision and 3D image analysis applied in the } \\
\text { context of virtual and augmented reality could find here } \\
\text { novel and game-changing applications. }\end{array}$ & $\begin{array}{l}\text { My hope for this panel is to foster the interdisciplinary } \\
\text { dimension of scientific research, both at the foundation and } \\
\text { application level, involving young and enthusiast researchers } \\
\text { from academia and research centers willing to tackle the } \\
\text { challenges in satellite communication systems. }\end{array}$ \\
\hline \multicolumn{3}{|l|}{$\begin{array}{l}\text { Nicola Conci, University of } \\
\text { Trento, Italy, IEEE Member }\end{array}$} \\
\hline $\begin{array}{l}\text { Maurizio Murroni, University of } \\
\text { Cagliari, Italy, IEEE Senior } \\
\text { Member }\end{array}$ & $\begin{array}{l}\text { Satellite communication is crucial to support the } \\
\text { broadcasting industry; currently, satellite broadcast } \\
\text { digital services are available worldwide and represent an } \\
\text { important market for the broadcasting stakeholders in } \\
\text { near future. Furthermore, broadband access via satellite } \\
\text { is gaining more and more space in the market while the } \\
\text { upcoming 5G scenario is focusing on the converged } \\
\text { satellite and terrestrial networks. In both scenarios the } \\
\text { development of new services driven by the user quality } \\
\text { of experience (QoE) is defining new generation satellite } \\
\text { broadband network configuration and management. QoE } \\
\text { assessment for broadband satellite communications is a } \\
\text { challenge for new generation satellite broadband network } \\
\text { performance improvement. Satellite stakeholders are } \\
\text { investing R\&D resources in this field looking at the } \\
\text { academia as references partners to this goal. I believe the } \\
\text { GLUE committee is the right place where this topic can } \\
\text { be addressed. }\end{array}$ & $\begin{array}{l}\text { The long term outcome of the panel should be leveraging the } \\
\text { creation of a critical mass of researchers able to address the } \\
\text { new challenges of satellite broadcast/broadband } \\
\text { communications. The short term outcome should be the } \\
\text { definition of the new challenges and trends to be pursued, } \\
\text { the dissemination of them within the research communities, } \\
\text { via the organization of dedicated workshops, summer } \\
\text { schools, seminars, keynote speeches in the major events, } \\
\text { such as international conferences and exhibitions. }\end{array}$ \\
\hline
\end{tabular}




\begin{tabular}{|c|c|c|}
\hline $\begin{array}{l}\text { Fabrizio Granelli, University of } \\
\text { Trento, Italy, IEEE Senior } \\
\text { Member }\end{array}$ & $\begin{array}{l}\text { I have been a member of IEEE ComSoc for several } \\
\text { years, and working on cellular and mobile networks I } \\
\text { often found it interesting to think about integrating those } \\
\text { effectively in the design of modern wireless networks. } \\
\text { This panel explores exactly this issue and clearly looks } \\
\text { into the future, by defining a clear step forward into a } \\
\text { more interdisciplinary approach to the design of future } \\
\text { satellite communications and at the same time paving the } \\
\text { way for integrating the best emerging technologies in } \\
\text { networking. }\end{array}$ & $\begin{array}{l}\text { In general, I expect the panel to identify a viable yet } \\
\text { revolutionary roadmap for the design and deployment of } \\
\text { novel approaches to satellite communications. Given the } \\
\text { competences of the involved experts, I hope this will } \\
\text { represent a firm example of how the interdisciplinary nature } \\
\text { and pervasiveness of communications should be successful } \\
\text { addressed, and exploited to bring a revolution in the field. }\end{array}$ \\
\hline $\begin{array}{c}\text { Tommaso Rossi, University of } \\
\text { Rome "Tor Vergata", Italy, IEEE } \\
\text { Member }\end{array}$ & $\begin{array}{l}\text { The panel is focused on stimulating thematic areas; as a } \\
\text { matter of fact, "glue technologies" concept is one of the } \\
\text { key topics in the current and future space-based systems } \\
\text { for communication, sensing and navigation applications. } \\
\text { 5G scenarios are leading us in the middle of a key } \\
\text { turning point and space systems have to play an } \\
\text { important role in such a complex and heterogeneous eco- } \\
\text { system. The panel will provide the opportunity to gather } \\
\text { experience from academy and industry to identify a } \\
\text { roadmap for the full exploitation of new technologies as } \\
\text { "softwarization" paradigms (both for the network and } \\
\text { radio interface) and terabit/s connectivity supported by } \\
\text { EHF. }\end{array}$ & $\begin{array}{l}\text { The main outcomes could be the dissemination of panel } \\
\text { activities through the organization of events, publications } \\
\text { and courses. } \\
\text { Moreover, it will be very important to create a strong liaison } \\
\text { between academic and industrial actors to push the } \\
\text { development of glue technologies, clearly identify the } \\
\text { challenges and train experts. }\end{array}$ \\
\hline $\begin{array}{l}\text { Shad Popescu, University of } \\
\text { Vlad } \\
\text { Transilvania, Brasov Romania, } \\
\text { IEEE Member }\end{array}$ & $\begin{array}{l}\text { Within the last years, the communication technologies } \\
\text { have generated significant interest to the concepts of } \\
\text { Internet of Things (IoT) and machine-2-machine (M2M) } \\
\text { communications. Even though initially exclusively of } \\
\text { terrestrial nature, these two concepts have shifted also in } \\
\text { the satellite R\&D domain, but are still conditioned by } \\
\text { elevated hardware and access costs. The software- } \\
\text { defined-radio (SDR) concept can contribute to the rapid } \\
\text { development of IoT and M2M systems by providing a } \\
\text { higher degree of flexibility in designing the wireless } \\
\text { communication interfaces both for the last-mile } \\
\text { terrestrial link as for the satellite links. Devices equipped } \\
\text { with SDR modules could dynamically switch between }\end{array}$ & $\begin{array}{l}\text { This panel should promote the seamless integration among } \\
\text { the vast range of technologies used for satellite } \\
\text { communication and navigation, focusing on the hardware re- } \\
\text { usability based in the software-defined-radio paradigm. This } \\
\text { would lead on the long term to the considerable reduction of } \\
\text { costs and time efforts and would also allow the rapid test } \\
\text { and adoption of new communication standards, especially } \\
\text { for the previously mentioned IoT and M2M applications. }\end{array}$ \\
\hline
\end{tabular}




\begin{tabular}{|c|c|c|}
\hline & $\begin{array}{l}\text { protocols and could also embed spectrum sensing } \\
\text { capabilities, useful both on terrestrial and satellite sides. } \\
\text { These research fields can be further extended to all types } \\
\text { of satellite communications and navigation systems and } \\
\text { also for robotic and human explorations in outer space } \\
\text { and on other planets. } \\
\text { The key term here is re-configurability and it implies } \\
\text { inherently a multidisciplinary approach: this panel can } \\
\text { help to promote the aforementioned concepts and find } \\
\text { new means and domains of application other than the } \\
\text { ones initially presented, one example in this direction } \\
\text { being the use in connected research fields such as } \\
\text { satellite broadcasting technologies. }\end{array}$ & \\
\hline $\begin{array}{c}\text { Michael Noble (L3Harris } \\
\text { Technologies, Melbourne, FL) }\end{array}$ & $\begin{array}{l}\text { Space is becoming increasingly important for functions } \\
\text { spanning all walks of life. From communications, to } \\
\text { position/navigation/timing, to imagery populating our } \\
\text { maps, use of space-based technologies touches virtually } \\
\text { every human on a daily basis. Moreover, the } \\
\text { international market for space systems is growing with } \\
\text { dozens of countries operating commercial, civil, and } \\
\text { military systems and many possessing the capability to } \\
\text { place these systems in orbit themselves. As this market } \\
\text { grows and continues to expand internationally, the IEEE } \\
\text { can serve this community by providing standards, } \\
\text { guidance on best practices, and opportunities for } \\
\text { technical exchange. }\end{array}$ & $\begin{array}{l}\text { My hope for this panel is it will assess the state and direction } \\
\text { of the space market, in particular for satellite systems but } \\
\text { necessarily for launch and operations as well. With this } \\
\text { knowledge, I expect this panel will make recommendations } \\
\text { to AESS and the IEEE on how best to serve this growing } \\
\text { community. For example, we may suggest a special edition } \\
\text { of the magazine dedicated to spacecraft system engineering } \\
\text { and common standards; this edition may become a } \\
\text { pathfinder for a dedicated publication. In addition, this } \\
\text { panel may suggest the modification of existing and } \\
\text { development of new technical standards for spacecraft. }\end{array}$ \\
\hline
\end{tabular}

